\title{
Maximum sustainable yield of trawl fishery along the south-west coast of India: Bayesian estimation approach
}

\author{
T. V. SATHIANANDAN, SOMY KURIAKOSE*, K. G. MINI AND P. K. SAFEENA \\ ICAR-Central Marine Fisheries Research Institute, Ernakulam North P. O., Kochi - 682 018, Kerala, India \\ e-mail: somycmfri@gmail.com
}

\begin{abstract}
The south-west region of the Indian coast is shared by three maritime states and it contributes nearly $32 \%$ to the total marine fish production of the country. Mechanised trawl fishery accounts for $44 \%$ of the marine fish harvest in the south-west coast and a number of resources are harvested by trawl nets from this region. An assessment of the trawl fishery to determine sustainable harvest levels for mechanised trawlers in the region was carried out using time series data on annual landings and fishing effort of mechanised trawlers during the period 1990-2015. A Bayesian estimation method for Schaefer model was used for the analysis. Posterior probability densities of parameters of the model, maximum sustainable yield (MSY) and corresponding biomass were obtained through Bayesian estimation for the trawl fishery in south-west coast and the harvest levels were found to be above MSY from 2012 onwards. Forecasts of biomass and fish landings by mechanised trawlers upto 2025 under different levels of fishing effort were also simulated using the model to study the dynamic changes over time. It was found that the numbers of multiday trawlers and single day trawlers operating in this region have to be reduced by 207 and 36 respectively to retain the harvest at sustainable level.
\end{abstract}

Keywords: Bayesian estimation, Biodynamic model, Maximum sustainable yield, Trawl fishery

\section{Introduction}

Marine fisheries forms an important sector in India with significant contribution towards the nation's GDP. Nearly 4 million marine fishermen depend on this sector for their livelihood (CMFRI, 2010). Among the 9 maritime states along the mainland of India, the three states Kerala, Karnataka and Goa, situated in the southwest region accounted for about $32 \%$ of the total marine fish production in the country during 2011-2015, though these three states cover only $17 \%$ of the total coastal length of the main land. Mechanised crafts which use trawl nets for fishing were the major fishing fleet in the fishery of the south-west coast contributing about $14 \%$ to the total marine fish production in the country. Mechanised trawlers contributed 34; 64 and 10\% to the total landings in Kerala, Karnataka and Goa, respectively (CMFRI, 2015). During the period 2013-15, 472 species were landed by mechanised trawlers along the south-west coast of which $95 \%$ was contributed by 65 species. Among these 65 species, 45 were common to all the three maritime states in the south-west coast accounting for $70 \%$ of the mechanised trawl landings and they form the basis for considering the region as a single ecosystem for the study. Being a natural resource with the capacity to rebuild, harvest of marine fishery resources needs to be managed based on periodic assessment of status of the fish stocks for maintaining sustained production from the sea. There are different approaches in fish stock assessment for deriving the management reference point "Maximum sustainable yield (MSY)". The method adopted here using time series data on fish catch and fishing effort as inputs with Schaefer model for describing the biomass dynamics is a widely accepted procedure. In addition, use of Bayesian methods for estimation of model parameters as well as MSY followed here is more appropriate as it yields posterior probability densities of each parameters and MSY, in place of the point estimates in other methods. Also, the Bayesian estimation approach provides opportunity to incorporate prior knowledge about the model parameters into the estimation process in order to prevent the estimates from falling in to logically non-acceptable regions. In India, for assessment of fish stocks, the methodologies adopted normally are micro level assessment of individual species using length measurements along with information on the quantity harvested and in some cases by analysing time series data on catch and effort. The Bayesian approach attempted here has the advantage that it pertains to a specific fishery so that the derived management measures can be directly implemented. The posterior probability densities derived through the Bayesian approach can be used to obtain confidence bands for MSY. Also, stochastic nature of biological processes involved in the dynamics of biomass is better accounted by the expression of reference points in terms of posterior probability densities. 
The basis of analysis in the current study is in line with the work by Meyer and Millar (1999a) in which they formulated the delay difference and surplus production models in to state-space modeling and designed a fully Bayesian approach for estimating posterior probability densities of parameters and MSY. They further demonstrated this using BUGS software that used Gibbs sampling to obtain posterior probability densities (Meyer and Millar, 1999b). There are many examples of application of biomass dynamics models and Bayesian estimation methods in fisheries in different parts of the world. Some of the important biomass dynamics modeling applications in fisheries are, age-structured stock dynamic model with stock size as unobserved variable and catches as observed variables (Lewy and Nielsen, 2003); hierarchical stock recruitment model used for European Atlantic salmon stocks (Prevost et al., 2003); biomass dynamic model based on logistic function for quantitative assessment, prediction and risk analysis of shrimp (Pandalus borealis) stock (Hvingel and Kingsley, 2006); two-stage biomass based state-space model for the Bay of Biscay anchovy population (Ibaibarriaga et al., 2008) and state-space surplus production models using the hammerhead shark complex of the Atlantic and Gulf of Mexico coasts (Jiao et al., 2009). Similarly, examples of works with Bayesian estimation approach in fisheries are stock assessment of Namibian hake (Merlucius capensis and M. paradoxus) by McAllister and Krikwood (1998); assessment of New Zealand's western stock of hoki (Macruronus novaezelandiae) and the Bering-Chukchi Beaufort Seas stock of bowhead whales by Punt and Hilborn (1997) and Bayesian analysis of stock-recruitment data of the Yellow Sea anchovy (Engraulis japonicus) by Wang et al. (2006). The present work which uses Bayesian estimation approach for estimating MSY is the first attempt of this kind in the marine fisheries sector of India.

\section{Materials and methods}

Time series data on annual marine fish landings during 1990 to 2015 by mechanised trawlers along with fishing effort, in terms of hours of operation, for the southwest coast of India was used for estimating MSY for the region. The approach adopted for estimation of MSY is Bayesian estimation using state-space model which consists of two basic equations as given below, one each for the process layer and the observation layer. The first equation describes the biomass in the next year in terms of the biomass and catch in the current year and the second equation links the observed catch and fishing effort to the unobservable biomass (Rankin and Lemos, 2015).

$$
\begin{aligned}
& B_{t+1}=B_{t}+h\left(B_{t}\right)-C_{t} \\
& I_{t}=q B_{t} e^{E t}
\end{aligned}
$$

where, $h\left(B_{\mathrm{t}}\right)$ is the growth in biomass as a parametric function of current biomass $B_{t} ; C_{t}$ is the fish catch and $f_{t}$ is the fishing effort during the year $t\left(I_{t}=C_{t} / f_{t}\right.$ is the catch rate which is considered as an index of biomass). Different models are available for different functional forms of $h\left(B_{t}\right)$ such as Schaefer model, Pella and Tomlinson model and Fox model (Rankin and Lemos, 2015). The last multiplier in equation (2) is to retain the stochastic nature of the observed quantities where $\varepsilon_{t}$ 's are assumed to be independent and identically distributed random variables with zero mean and constant variance $\sigma^{2}$. The parameter $q$ in equation (2) is termed as the catchability coefficient which indicates the proportion of biomass obtained as catch per unit of fishing effort. If $F_{t}$ represents the fishing mortality then its relationship with fishing effort is $F_{t}=q f_{t}$ and hence $C_{t}=F_{t} B_{t}$. The model used for the study here is the Schaefer model for which $\mathrm{h}\left(\mathrm{B}_{\mathrm{t}}\right)=\mathrm{rB}_{\mathrm{t}}\left(1-\frac{\mathrm{B}_{\mathrm{t}}}{\mathrm{K}}\right)$ leading to equation (3) for the process layer of the model.

$$
B_{t+1}=B_{t}+r B_{t}\left(1-\frac{B_{t}}{K}\right)-C_{t}
$$

For this model, the expressions for estimating MSY and corresponding fishing effort and biomass are given below.

$$
\mathrm{MSY}=\frac{\mathrm{rK}}{4} ; \mathrm{E}_{\mathrm{MSY}}=\frac{\mathrm{K}}{2 \mathrm{q}} ; \mathrm{B}_{\mathrm{MSY}}=\frac{\mathrm{K}}{2}
$$

Parameters of the model from equations (2) and (3) are carrying capacity $K$, intrinsic growth rate $r$, catchability coefficient $q$, the biomass sequence and variance of the error term $\sigma^{2}$. The core of Bayesian approach in statistics is the theorem known as Bayes' rule developed by Bayes (1763) to describe the probability of an event based on prior knowledge of conditions that could be related to the event. With the advent of modern computing power, the method which was dormant for more than a century due to complex calculation requirements, evolved into a new branch with varying applications in different fields of research including fisheries. In the conventional maximum likelihood method of estimation the model parameters are estimated by maximising the likelihood which is nothing but the probability of the observed data for given values of parameters denoted by $P(\operatorname{data} / \theta)$. The major advantage of Bayesian approach is that instead of a point estimate for the parameters, it provides us opportunity to estimate probability distribution functions foreach parameter, termed as posterior probability densities, denoted by $P(\theta /$ data $)$. This as per the Bayes' rule is given by:

$$
\mathrm{P}(\Theta / \text { data })=\frac{\mathrm{P}(\text { data } / \Theta) \mathrm{P}(\Theta)}{\mathrm{P}(\text { data })}
$$


Here, $P(\theta)$ indicates the prior probability (prior knowledge) about the parameter and $P($ data $)$ is the overall sum of the quantity in the numerator for all possible values usually obtained through a grid search.

The calculations for obtaining estimates of prior distribution parameters for lognormal and inverse-gamma probability distributions were made using Parameter Solver Version 2.3.0 (https://biostatistics. mdanderson. org). For Bayesian estimation of MSY, prior distributions for the parameters were calculated by setting up 10 and $90 \%$ quantiles based on the initial estimates obtained through Genetic algorithm approach (Sathianandan and Jayasankar, 2009). The development of Markov Chain Monte Carlo (MCMC) simulation algorithms such as the Gibbs sampling provided a general alternative tool for numerical integration necessary for calculating $P($ data $)$. The MCMC methods simulate direct draws from complex probability distributions of interest and it is termed Markov Chain, because only the previous sample values are used to randomly generate the subsequent sample value.

In this study, the software used for Bayesian estimation of posterior probability densities of parameters of the models and the maximum sustainable yield is the free ware OpenBUGS (version 3.0.3) developed by the Medical Research Council Biostatistics Unit, Cambridge and Imperial College School of Medicine, London. In OpenBugs, the estimation is based on MCMC algorithm using Gibbs sampling. Necessary command script in the software environment for the model was developed following the guideline given by Mayer and Millar(1999b). For estimation using the data set, 1.1 million simulations were made and only the last 1 million simulations were used in the calculations, ignoring the initial simulations for the sake of convergence. Also, thinning of the generated samples to avoid auto-correlation of samples was implemented by considering every $3^{\text {rd }}$ sample only, for the calculations through the option available in the software. Iteration history and posterior probability densities were examined after completing the simulations.

Using the final estimated model, forecasts of biomass and fish catch of the trawl fishery were made for a period of ten years under different levels of fishing efforts viz., maintaining effort at current level, keeping effort at 5 and $10 \%$ higher than the current level and reducing effort by 5 and $10 \%$ from the current level. The current level of fishing efforts for the future ten years were generated using normal distribution with mean and standard deviation of the fishing effort observed during the last five years of the study period. For other situations, the fishing effort were generated in a similar way by drawing from normal distributions with means suitably increased or reduced.

\section{Results and discussion}

The marine fish landings by trawlers in the southwest coast of India during 1990-2009 fluctuated from 0.3 to 0.4 million t except in 1994 when it crossed 0.4 million t. From 2010 onwards it showed a steady increase and reached 0.54 million $t$ in 2015. The percentage contributions by the states of Kerala, Karnataka and Goa during the five-year period from 2011 to 2015, towards the total landings of south-west coast were 42.9, 55.3 and $1.8 \%$ respectively. Plots of observed landings and catch rates of trawlers for the three states as well as for the whole south-west region are shown in Fig. 1 anddetails of the fitted trend models are given in Table 1. From Fig. 1 it is clear that the landings in south-west region increased over the years during 1991-1995 from 0.29 million $t$ to 0.44 million $\mathrm{t}$ and fluctuated around 0.33 million $\mathrm{t}$ thereafter until 2008. Further, during 2009-2012, it increased to reach 0.57 million $t$ and subsequently settled around 0.5 million $t$. However, the three states had varying trends in their marine fish landings during this time period. The trawl landings in Kerala during 1994-2010 showed a marginal downward trend with slight increase thereafter, whereas the trawl landings of Karnataka showed a slight upward trend throughout the period. The trawl landings in Goa showed a steep downward trend with oscillations. Though the landings by trawls in Kerala increased in the initial few years to cross 0.3 million $t$ in 1994, it showed a continuous decline thereafter to reach the minimum of 0.15 million $t$ in 2007. In Karnataka the trawl landings experienced a six-fold increase from 0.05 million $t$ in 1990 to 0.32 million $t$ in 2015. In the case of Goa, the trawl landings initially had a steep increase from 0.01 million $t$ in 1990 to 0.04 million $t$ in 1994 but had a steep fall back to 0.01 million $t$ in the next year. Thereafter it fluctuated in a cyclic manner with downward trend to reach 0.012 million $t$ in 2015. Thus, it was clear that all three states had different trends in their trawl landings which could be attributed to the skill of the fishermen, different fishing

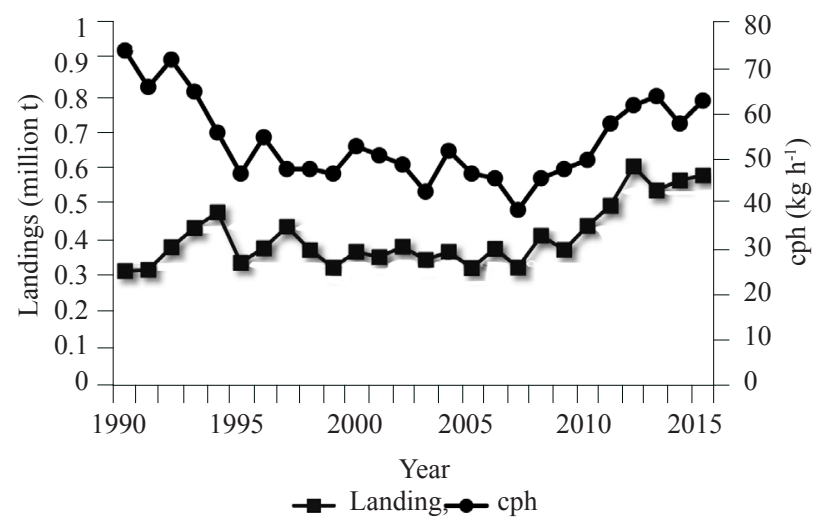

Fig. 1. Plot of observed trawl landings and catch rates for south-west region of India 
Table1. Bayesian estimates of parameters and reference points along with standard deviation and confidence interval for the trawl fishery in south-west region of India

\begin{tabular}{lllll}
\hline Parameter & Mean & Standard deviation & \multicolumn{1}{c}{ Confidence Interval (97.5\%) } \\
\hline K & 5478000 & 1929000 & 2710000 & 10300000 \\
$\mathrm{r}$ & 0.3965 & 0.1214 & 0.1968 & 0.6697 \\
$\mathrm{q}$ & 0.01421 & 0.00552 & 0.00617 & 0.02741 \\
MSY & 501600 & 124700 & 336700 & 820800 \\
BMSY & 2739000 & 964300 & 1355000 & 5150000 \\
sigma2 & 0.00697 & 0.00278 & 0.00304 & 0.01373 \\
tau2 & 0.00429 & 0.00220 & 0.00156 & 0.00985 \\
\hline
\end{tabular}

grounds, variable growth in the number of trawlers of each state and fisheries management policies of each state.

The average catch rate of trawlers in the south-west region declined over years during 1990-1995 from $71 \mathrm{~kg}$ $\mathrm{h}^{-1}$ to $44 \mathrm{~kg} \mathrm{~h}^{-1}$ and thereafter it fluctuated around $45 \mathrm{~kg}$ $\mathrm{h}^{-1}$ till 2007 (Fig. 1). From 2008 onwards the catch rate showed an upward trend to reach $60 \mathrm{~kg} \mathrm{~h}^{-1}$ in 2013 and fluctuated around this value thereafter. As with trawl landings, the catch rate also varied among the three states in the south-west region. The annual average catch rate of trawlers in Kerala behaved like a U-shaped parabola (opened upward) with the vertex coinciding with the year 2008 and catch rate $45.7 \mathrm{~kg} \mathrm{~h}^{-1}$. Time series on catch rate of Karnataka also fitted well like a U-shaped parabola with catch rate decreasing in the initial years and later gradually increased. The fitted parabola has its vertex corresponding to year 1998 with catch rate of $32.9 \mathrm{~kg} \mathrm{~h}^{-1}$. From the trends of the two states it is clear that towards the second half of the study period, the trawl catch rates of Karnataka increased at a steeper rate than Kerala. The catch rate for trawlers in Goa could not be reasonably represented by a suitable trend model as the fitted polynomial of higher degrees yielded poor fit. A polynomial of degree 4 was found to explain the trend in observed catch for the south-west region where as the catch trend was suitably explained by a U-shaped parabola. The parabola fitted for catch rate had its vertex corresponding to year 2003 with catch rate $45.6 \mathrm{~kg} \mathrm{~h}^{-1}$.

Prior distributions for $K$ and $r$ were set as lognormal with 10 and $90 \%$ quantiles at $(900,2200)$ and at $(0.2,2.5)$ respectively. Prior distribution for $q$ was taken as inverse gamma and prior distributions for process error as well as observation error variances were taken as inverse gamma with 10 and $90 \%$ quantiles at $(0.04,0.08)$ and $(0.05$, 0.15 ) respectively. Estimates of posterior probability densities of the model parameters were obtained from 1.1 million simulations through Gibbs sampling leaving the first 0.1 million for attaining convergence and thinning by considering only every third sample in the calculations. History plots of all the parameters showed uniform oscillations around the final estimates throughout the simulation, after the initial burning. The estimated posterior probability density plots of parameters of the model namely carrying capacity $K$, intrinsic growth rate $r$, catchability coefficient $q$, maximum sustainable yield (MSY) and biomass corresponding to MSY level ( $\left.\mathrm{B}_{\mathrm{MSY}}\right)$ are given in Fig. 2. Also, the procedure yielded posterior probability density estimates of biomass for each year.
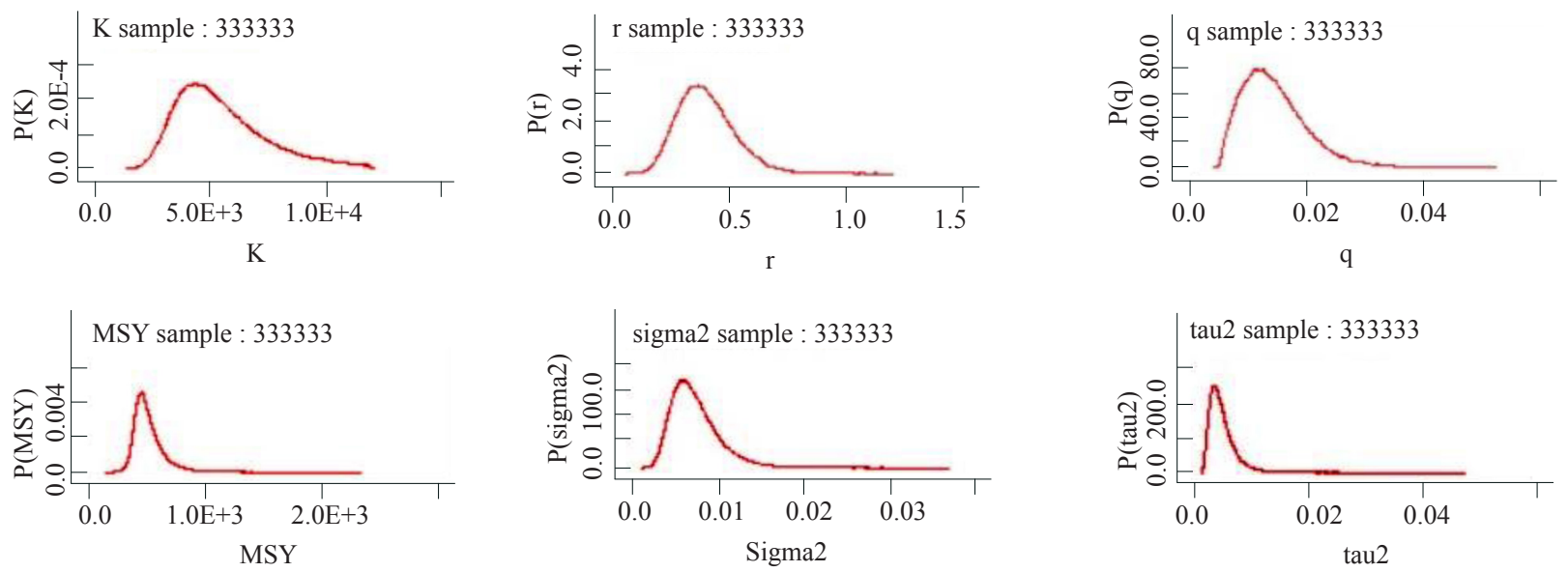

Fig. 2. Plot of Bayesian estimate of posterior probability densities for different model parameters and MSY for the trawl fishery in south-west region of India 
The mean and standard deviation of the parameters were calculated based on their posterior probability densities and subsequently the biomass over the time period is estimated and plotted along with observed landings and MSY (Fig. 3).

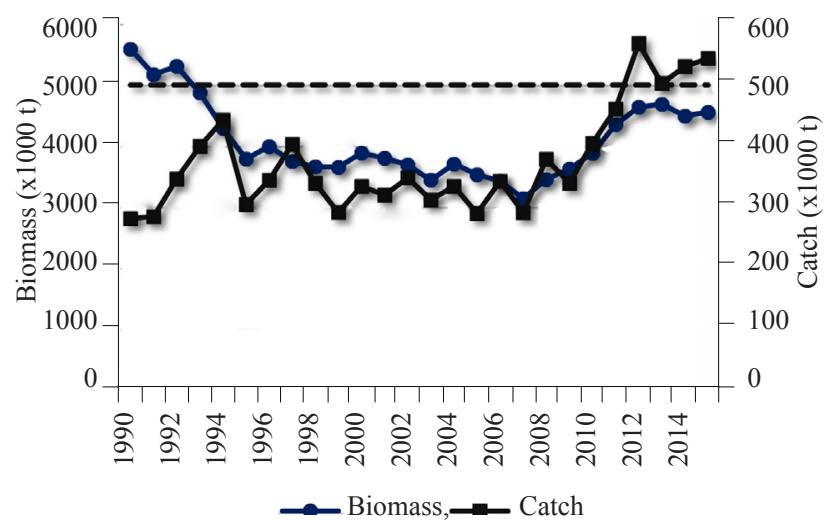

Fig. 3. Plot of observed trawl landings and biomass estimates along with MSY (dotted line) for the south-west region of India

Sensitivity of the initial values set for $K, r$ and $q$ for setting up the prior distributions in estimation of posterior probability densities of MSY was also examined by changing the initial values and re-estimating MSY. The results indicated that, for $1 \%$ change in the initial values, the maximum percentage change observed in MSY estimates were $0.31 \%$ for both $K$ and $r$ and $0.17 \%$ for $q$. MSY estimates were thus more sensitive to changes in $K$ and $r$ than to changes in $q$.

The final Bayesian estimate of MSY for trawlers in the south-west region was 5,01,600 t and the observed landings were above MSY from 2012 onwards. The landings exceeded the MSY by $13.6 \%$ in 2012. Even though the exploitation was done at more or less equal to MSY level in 2013, it increased in the next two consecutive years, exploiting at higher than MSY level by $6 \%$ and $8.7 \%$. Thus, it is evident that trawl fishing in the south-west region of the country has turned increasingly unsustainable.

Fish stock assessment and projections often aid in evaluating responses of fishery to different management plans (Hilborn and Walters, 1992). To examine the expected dynamic changes in biomass as well as fish catch when fishing effort levels are altered, forecasts of biomass and fish catch were made for the years up to 2025 for five different levels of fishing effort (Fig. 4 and Fig. 5). It was found that the biomass sequences for the future years had steady declining trend when exploitation level was

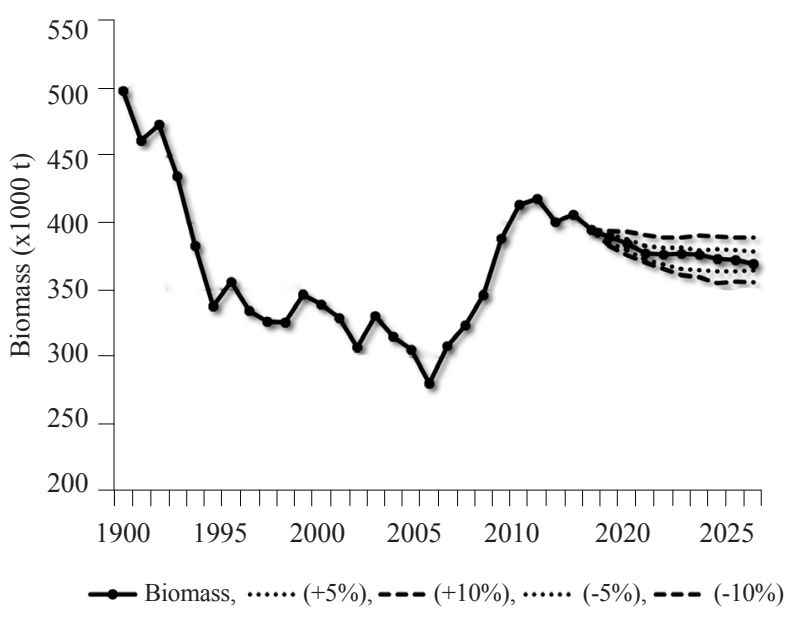

Fig. 4. Forecasts of biomass for the trawl fishery in south-west region of India at different levels of fishing effort

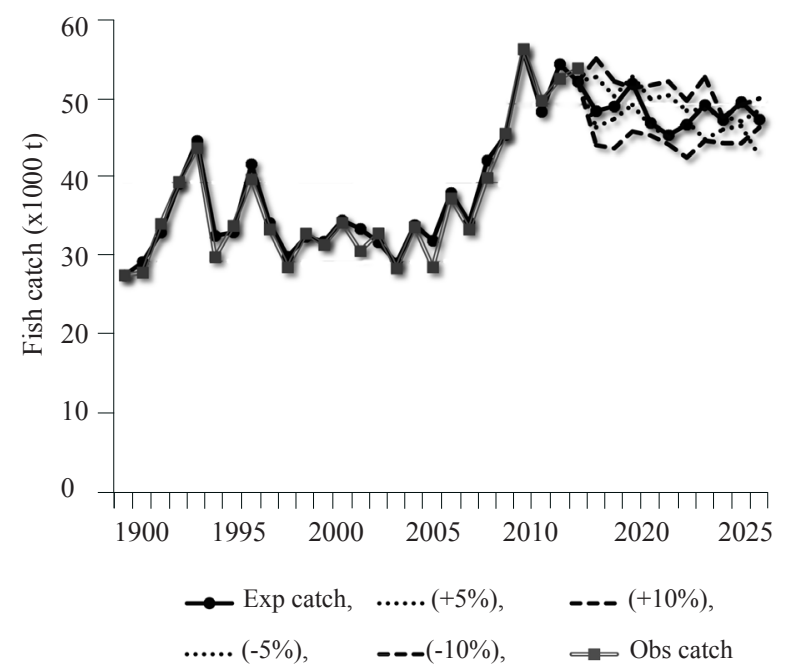

Fig. 5. Forecasts of fish catch for the trawl fishery in south-west region of India at different levels of fishing effort

maintained at the current level or higher and an increasing trend when exploitation levels were reduced. The expected catch in the future years was found to be highly fluctuating over years for all the four levels of fishing effort. From the model predictions, it is clearly evident that the impact of changing fishing effort would be highest on biomass than on marine landings of the study region. It is further evident that any increase in fishing effort in the region can only lead to further unsustainability of the fishery. This can be a useful argument for convincing fishermen to regulate fishing effort in the south-west coast of India.

A major reason attributed to unsustainable fishing is overcapacity in the fishing fleet of a region. The number of trawlers including both single day and multiday, operating 
in Kerala, Karnataka and Goa were 3678, 2847 and 834 respectively (CMFRI, 2012). The optimum fleet size proposed by the revalidation committee (Anon., 2011) for these states respectively are $2489,1312,133$ for multiday trawlers and 1121, 729, 191 for single day trawlers. Hence currently Kerala operates with $2 \%$ excess trawl capacity and Karnataka with 39\%. In the case of Goa, the existing trawl fleet is 1.6 times higher than the proposed optimum fleet. The single day and multiday trawlers on an average make 240 and 60 trips per annum respectively and the multiday trawlers operate for $30 \mathrm{~h}$ per trip whereas the single day trawlers operate for $7 \mathrm{~h}$ per trip (Sathianandan et al., 2008). In the south-west region, the average catch per hour during the period 2011-2015, for multiday trawlers was $61 \mathrm{~kg}$ and that for single day trawlers was $42 \mathrm{~kg}$. The expected average annual harvest by trawlers in south-west region corresponding to the fleet size recommended by the revalidation committee based on this information is $5,75,600 \mathrm{t}$ which is still 74,000 $\mathrm{t}$ higher than the estimate of MSY obtained in this study. The average landings by trawlers in the south-west region for the last three years is $5,26,900 \mathrm{t}$ of which $89 \%$ is contributed by approximately 4250 multiday trawlers and the remaining $11 \%$ by 820 single day trawlers. This is in excess by $5 \%$ to the estimated MSY and hence, to bring down the exploitation level to MSY, the numbers of multiday and single day trawlers in south-west region should be reduced by 207 and 36 respectively. Reduction in fleet size is a challenging task for any fisheries management authority. However, fisheries managers of the three states need to jointly chalk out a fleet reduction strategy for the region which ensures that the fishery operates within the MSY level. Ensuring stakeholder participation in the decisionmaking process will ensure that fleet reduction can be a success and that the trawl fishery of the south-west coast of India remains sustainable in the coming years.

\section{Acknowledgements}

The authors sincerely thank Dr. A. Gopalakrishnan, Director, ICAR-CMFRI, Kochi for the encouragement during the preparation of this manuscript and also for providing necessary facilities for the conduct of the study.

\section{References}

Anon. 2011. Report of the working group for revalidating the potential of fishery resources in the Indian EEZ. Department of Animal Husbandry, Dairying and Fisheries, Ministry of Agriculture, Govt. of India, New Delhi, 69 pp.

Bayes, T. 1764. An essay toward solving a problem in the doctrine of chances. Phil. Trans. R. Soc. Lon., 53: 370-418. doi: 10.1098/rstl.1763.0053.
CMFRI 2012. Marine fisheries census 2010 India. ICARCentral Marine Fisheries Research Institute, Kochi and Department of Animal Husbandry, Dairying and Fisheries, Ministry of Agriculture, New Delhi, Govt. of India, 98 pp.

CMFRI 2012. Marine fisheries census 2010 India. ICARCentral Marine Fisheries Research Institute, Kochi and Department of Animal Husbandry, Dairying and Fisheries, Ministry of Agriculture, New Delhi, Govt. of India, 98 pp.

CMFRI 2015. Annual report 2014-15. ICAR-Central Marine Fisheries Research Institute, Kochi, India, 353 pp.

Hilborn, R. and Walters, C. J. 1992. Quantitative fisheries stock assessment: Choice, dynamics and uncertainty. Chapman and Hall, New York, USA, 570 pp.

Hvingel, C. and Kingsley, M.C.S. 2006. A framework to model shrimp (Pandalus borealis) stock dynamics and to quantify the risk associated with alternative management options, using Bayesian methods. ICES J. Mar. Sci., 63: 68-82. doi:10.1016/j.icesjms.2005.09.002.

Ibaibarriaga, L., Ferna'ndez, C., Uriarte, A. and Roel, B. A. 2008. A two-stage biomass dynamic model for Bay of Biscay anchovy: a Bayesian approach. ICES J. Mar. Sci., 65: 191-205.

Jiao, Y., Hayes, C. and Cortes, E. 2009. Hierarchical Bayesian approach for population dynamics modelling of fish complexes without species-specific data. ICES J. Mar. Sci., 66: 367-377.

Lewy, P. and Nielsen, A. 2003. Modelling stochastic fish stock dynamics using Markov Chain Monte Carlo. ICES J. Mar. Sci., 60: 743-752. DOI: 10.1016/S1054-3139(03)00080-8.

Meyer, R. and Millar, R. B. 1999a. Bayesian stock assessment using a state-space implementation of the delay difference model. Can. J. Fish. Aquat. Sci., 56: 37-52.

Meyer, R. and Millar, R. B. 1999b. BUGS in Bayesian stock assessments. Can. J. Fish. Aquat. Sci., 56: 1078-1086.

McAllister, M. K. and Kirkwood, G. P. 1998. Bayesian stock assessment: a review and example application using the logistic model. ICES J. Mar. Sci., 55(6): 1031-1060. https://doi.org/10.1006/jmsc.1998.0425.

Prevost, E., Parent, E., Crozier, W., Davidson, I., Dumas, J., Gudbergsson, G., Hindar, K., McGinnity, P., MacLean, J. and Sættem, L. M. 2003. Setting biological reference points for Atlantic salmon stocks: transfer of information from data-rich to sparse-data situations by Bayesian hierarchical modelling. ICES J. Mar. Sci., 60: 1177-1193.

Punt, A.E. and Hilborn, R. 1997. Fisheries stock assessment and decision analysis: the Bayesian approach. Rev.. Fish Biol. Fish., 7: 35-63.

Rankin, P. S. and Lemos, R. T. 2015. An alternative surplus production model, Ecol. Model., 313(C): 109-126.

Sathianandan, T. V., Jayasankar, J., Vivekanandan, E., Narayanakumar, R. and Pillai, N. G. K. 2008. Estimates on potential yield and maximum sustainable fleet size for 
marine fisheries in Kerala. J. Mar. Biol. Ass. India, 50(2): 196-201.

Sathianandan, T. V. and Jayasankar, J. 2009. Managing marine fishery in Kerala through simulation using surplus production model, genetic algorithm and spectral methods. Indian J. Fish., 56(3): 161-168.

Wang, Y., Liu, Q. and .Ye, Z. 2006. A Bayesian analysis on the anchovy stock (Engraulis japonicus). Fish. Res., 82: 87-94.

Date of Receipt $\quad: 31.03 .2015$

Date of Acceptance : 7.02 .2020 